\title{
The Discussion Based on the Relationship between the Teachers and the Students of Higher Education in the New Period
}

\author{
Kun Zhang \\ College of Resources \& Environment \\ Hunan Agricultural University \\ Changsha, China \\ zhangkun@hunau.net
}

\author{
Ting Huang* \\ Horticulture \& Landscape College \\ Hunan Agricultural University \\ Changsha, China \\ huangting@hunau.net
}

\begin{abstract}
In the reform system of education in the new period, teacher-student relationship should be the focus of public attention. According to the analys is of the disharmony factors of the communication between teachers and students, and combining with the characteristics, the authors had put forward some measures, which include one new version teacher dignity and the principles of Confucius "benevolence". Through analys is, it is necessary to pay attention to the relationship between teachers and students, and which can effectively improve the quality of students training, promote the harmonious development of society and deepen the reform of education in colleges and universities.
\end{abstract}

Keywords-teacher-student relationship; college students' training; reform of high-education

\section{INTRODUCTION}

In the system of higher education reform in the new era, teacher-student relationship should be the focus of attention. Higher education belongs to a high level of talent cultivation, the relationship between teachers and students of higher education should be formed in the full of democracy and freedom, justice, honest and friendly, vitality, natural and harmonious atmosphere. A good teacher-student relationship is a prerequisite for effectively improving education teaching quality, improving teachers' social influence and improving students' comprehensive quality level. From Wang Yu-cheng of Fudan University were in court with his academician tutor and Soochow University student report guidance teacher plagiarized his thesis achievement, all the information shows the discord between the teacher and the student. Teacherstudent discord will lead to the public crisis of higher education directly; shake the teacher's direct divine status.

In the long run, it will not only make the further strain relations between teachers and students in colleges and universities, but also make quality talents cultivation become an empty talk. During the period of higher education development and reform, teacher-student relationship only seriously is analyzed from the essence of connotation and denotation, which will be the true guidance to establish good relationship between teachers and students

Research Projects: Research on the development of multi-dimensional view of land resource management.(HUNAU,2017079).

\section{PRoBlem Finding}

\section{A. Cold relationship with teacher, close relationship with school counselor}

In contemporary universities, one management method had been wildly used which namely the teacher is responsible for the college students' study, and school counselor is responsible for the daily life of the college students. With the impact of the group type teaching mode and the limited class time, it was very difficult to have a further communication opportunity for the teacher and students in the classroom, and after class it was also hard to have time to communication with each other. Outside the classroom, the management of students' activities and daily life in the dormitory is almost always held by the counselor, and the teachers have little chance to participate in management. The teacher is only responsible for the study of one or two courses of college students, while school counselor accompanies the college students from the entrance to the graduation. To some extent, this has resulted in the close relationship between most college students and counselors, and the relative estrangement between students and teachers.

Although this kind of phenomenon has close relation with the specific division function of teacher and counselor. But what is undeniable is that the management model does to more extent on the relationship between the teaching teachers and students.

\section{B. More comm about exams, rarely comm about academic issues}

Social competition and employment pressure were the problems those all college students and education workers must face together. Therefore, students will inevitably encounter topics such as CET (College English Test), postgraduate entrance examination and civil servant exam in the university education.

To be sure, the test-taking skills of these tests are really important and will have an impact on the ability of college graduates to improve their skills and employability.

However, too much emphasis on the topic of examination skills, which can cause the loss of university academic 
atmosphere, reduce further deep discussions about learning, students' comprehensive quality and practical ability will be not effectively improve. Lacking of comprehensive quality and ability of university graduates will leading to the loss of adapt and strain capacity within rapidly changing social development, harmonious relationship between teachers and students it will be difficult to have good quality.

\section{In class, the teacher always gives lectures and rarely allows studuents to questions}

In classroom, due to the large number of students and relatively few teachers, there is only one one-to-many teaching method. Within this relative "single rigid" teaching mode by "teacher speak, students listen ", the teacher is very difficult to consideration for each student's learning experience, it is impossible to get in effective exchange and communication with each student.In class, it is often seen that the teacher is on the platform by speaking with a flow of words, sweating like rain.Some students who have not kept up with the progress of the teacher's lectures are sleeping on the table.

This kind of cramming a liberal education, within lack of effective interaction during the teaching process, students were more easily for losing the learning interest, even will produce the emotions such as learning disabilities, careless, despise, truancy, harmonious relationship between teachers and students will not existed under this kind of circumstances for granted.

\section{ANAlysis of the PROBLEM}

By analyzing the above problems, some factors those because problems were analyzed.

\section{A. The contradiction between the growth of student Numbers and the relatively backward teaching resources}

The development of education was the embodiment of the progress of social civilization, and the increasing of the number of college students also alleviates the contradiction of the relative shortage of social talents to a certain extent and ensures the progress and development of the society.

But at present, the increasing rate of teaching resource compared with the growth in the number of the college students, relative lag, the short-term conflict cannot be ignored, which also affect the harmonious development of the relationship between teachers and students to a certain extent.

\section{B. The teaching evaluation system lacks the relevant content of teacher-student relationship evaluation}

For colleges and universities, teachers' teaching level and the comprehensive quality of decision mainly includes scientific research, the paper, the requirements of teaching workload and so on, which general lack of judgment standard of harmonious relationship between teachers and students or not.

At present, the evaluation of teachers' teaching quality was mainly from two aspects: teaching supervision group evaluation and student evaluation.
For teaching supervision group, subject to the supervision of heavy workload, one teacher's teaching quality evaluation tend to adopt the way to evaluate one class (only 45 minutes), as long as teachers grasp the 45 minutes, they will get the honorary title with old hand of teaching.

For students, although can evaluate teachers in some more advanced educational system, but they generally found that the rule is overall evaluation of the whole process of teaching at the end of the course, rather than evaluation in real time in the process of teaching.

In this simple and easy operation evaluation system, teachers no longer focus on the teaching art, they would like focus on supervision of 45 minutes in class for teaching supervision group, they would also focus on the summative evaluation from students, and not focus on the real-time evaluation of students in the process of teaching with targeted to the improvement of teaching means.

The lack of this kind of decision criteria of the relationship between teachers and students that the concept of teacher education standard inversion, teachers worried something such as their scientific research, the thesis and teaching work which directly linked to their titles, while neglecting the cultivation of teacher-student relationship, teaching had been one empty talk.

\section{Students were subject to the influence of classical campus lifestyle and neglect to communicate with teachers}

College students will easily been influenced by some factors, in addition to learning task completion step by step, they kept on performing basic is "classroom-canteendormitory" three point one line monotonous process. During their four years studying in campus, many students even don't know where is the department office, which teaching and research office did their teachers belong to. With such lifestyle, of course it was difficult to oneself for learning professional, being interested in academic field or has some in-depth discussion with his teacher.

Is well documented, in the $1980 \mathrm{~s}$ college students may be attracted by Nietzsche and Hegel in the library, or go to study some professional interest problem, but today, more students go to the library for self-study, only preparing for English CET exams, postgraduate entrance examination and the civil service exam. In this way, students will lose their own interest and academic faith gradually, lost the opportunity to communicate effectively with the teacher.

\section{The potential conflict between teachers and students' ideology}

Campus, is the personnel intensive place. Teachers and students there have higher level of education and high mental state. There are big differences for each other such as ideal, belief, morality, culture, etc. Therefore, teachers and students in colleges and universities inevitably have conflicts of value idea, emotional identity and role playing.

On college campuses, to some extent, teachers want students to be "good students" who follow the rules, love learning, and actively cooperate with their own teaching tasks. Students want to be able to meet "handsome teachers" who are 
both humorous and elegant, who share a common interest and taste and are not taught in the usual way. But the teacher's academic view and the research direction, and the different styles of lecture, students' learning interest, different individual hobby, directly led to the gap between reality and ideals whether it is student's expectations of the teacher or the teacher's expectations of the students. At the same time, something like college students' individual differences, uncompleted psychological transition from high school to college, and unequal communication between teachers and students which often make teachers complain about students is difficult to teach, and students complain of teacher perverse things happen, this is also to a certain extent affect the harmony and development of the relationship between teachers and students.

\section{Measures and Suggestions}

The particularity of teacher-student relationship in the new period cannot be solved by conventional analysis, and special measures and suggestions need to be obtained by special analysis.

\section{A. Play down the "dignity of the teacher" and advocate caring for students}

In traditional Chinese culture, teacher-student relationship emphasizes more on the etiquette of respecting teachers and teaching, and conveys the idea of "a teacher of one day is a father of a lifetime”. In accordance with such a teacher-based relationship between teachers and students, apart from the "loving mother more defeated son", teachers are more responsible for the strict father's role of absolute authority. The majesty of the teacher may be the only part of the student's fearfulness, obedience, and rebellion. This alienated teacherstudent relationship often causes our students to lose their ability of thinking, analyzing and solving problems systematically.

In the new era, the stereotype of "a strict teacher produces excellent students" not only can hurt students' enthusiasm, suppress students' thinking, but also may have negative impact on the students' learning effect and cultivation of their own abilities. Therefore, encouraging teachers to communicate with students is the first priority.

Teachers and students communicate, can follow the principle of easy, freedom, equality of communication, that equality should be based on personality on the basis of equality, can't let students feel the teacher in the process of communication "authority" and "cold", most college students were far away from home, the teacher should know the perspective-taking, take the initiative to act students feel as "meet an old friend in a distant land".

B. Carry forward the principle of "benevolence" of Confucius, forgive others and take good care of students

To some extent, college students are young, pure, with infinite curiosity of the unknown, and full of vigor, but they are soft, they cannot keep calm in a crisis. They lack sufficient thinking on many issues. Their trust and distrust of teachers related on both the social level and on teachers' own quality.
Money worship, and materialistic society those might played a negative role of viewing the relationship between teachers and students, but more important, teacher's words and deeds was the main factor to determine their relationship harmonious or not. Efforts to deal with the relationship between teachers and students, the key of which is to grasp cultivating teacherstudent relationship is a kind of art, namely we can't blindly indulging students' pure, let students neither bewilder in the face of complex society, nor can they create one "too realistic" concept with teachers.

\section{Take the student as the main body, set up the idea of serving for the student wholeheartedly}

Student is the main part in the college campus. The teacher not only is hard gardener, but also is human soul engineer. Be a good teacher, not only deeply understanding the connotation of occupation, but also must set up the idea of serving the students wholeheartedly. The relationship between students and students should be dealt with both art and technology. How to master this technology, to promote the art of communication between teachers and students to the extreme, which can be listed as one compulsory and intensive studying course of college teacher in addition to the academic research. In the process of dealing with teachers, college students may be in a passive position due to their lack of life experience and social experience. Therefore, it is necessary to encourage teachers to actively communicate with students.

Encouraging teachers and students exchanges, in addition to build system of regular meetings between teachers and students, handle the relationship between teachers and students discussion as a long-term teaching and researching activities to carry out, which also can be detailing the specific contents of communication mode and communication places. This can provide effective guidance and help for the communication between teachers and students. At the same time, integrating the teacher-student relationship into the teacher ethics evaluation system, which can effectively urge teachers to pay attention to the relationship between teachers and students and form a catalyst for the relationship between teachers and students. Teachers' evaluation can include evaluation indicators such as whether students are interested in teaching, whether teachers are concerned about students, and whether they encourage students to ask questions.

\section{Teacher should take into account the functions of "teaching and giving"}

In addition, teachers should take on the responsibility of students 'teaching and students' learning.In today's information society, in the era of knowledge explosion, there are many ways and methods for students to acquire knowledge.Although in addition to studying in the class, students can also gathered knowledge from internet, but how also cannot compare with the teacher's subtle influence on the students.Mission Tuition, not only is a profound reflection of "It is better to teach the fish than to give it a fish ", but also is one necessary factor for the long-term harmony between teachers and students. 


\section{CONCLUSION}

To believe that good relationship between teachers and students, which not only is the premise for teacher intend to work smoothly, but also is the premise for students' comprehensive ability trainings.A good relationship between teachers and students needs to be studied and paid attention to by the society. It requires the efforts and attentional efforts of the administrators of colleges and universities. It is necessary for all education workers to study and discuss with each other.The direct purpose of establishing a good teacher-student relationship is to cultivate students who exceed teachers and provide effective talents for social progress.

\section{ACKNOWLEDGMENT}

This research is supported by the following projects:

Research project of Hunan Agricultural University admissions "Categories of land resources management professional multidimensional perspective of connotative development research"(2017079);

Research project of Hunan Agricultural University Oriental Institute of Science and Technology "Independent institute of land resources management talent education research" (2015039).

\section{REFERENCES}

[1] John S. Brubacher, Philosophy of Higher Education, School Review, U.S.A., vol.4, 1978

[2] John Henry Newman. The Idea of a University, Foreign Language Teaching and Research Press, China, September 2015

[3] SUN J.S, XIE L.L. The research paradigm of contemporary teacherstudent relationship in China which was abandoned and surpassed (in Chinese).Journal of the Chinese Society of Education, vol.4, pp 44-47, April 2004.

[4] YANG Y.Y. The discussion based on the harmonious relationship between teachers and students (in Chinese). Hubei Society Science.vol.11, pp 151-153, November 2005

[5] LIU H. Intercourse: A new concept of relationship between teachers and students (in Chinese).Journal of teachers college of Shan xi University. vol. 4, pp 78-81, April.2001.

[6] LUO J.Y. To build a harmonious relationship between teachers and students. The party building and ideological education in schools. vol.6, pp 66-67, June.2007.

[7] WANG L.W. The research on the issue of teacher-student relationship combined with my teaching experiences. Northeast Normal University.2010.

[8] LIU F. The construction of the harmonious teacher-student relationship in higher institutions based on conversation theory. Hunan Agricultural University. 2008 